\title{
Synofit Premium in Refractory Low Back Pain: A Retrospective Observational Study
}

\author{
Jiangan $Q u^{1 *}$, Christian Mélot², Thierry Appelboom ${ }^{1}$ \\ ${ }^{1}$ Dept. of Rheumatology and Physical Medicine, Iris Sud Hospital, Brussels, Belgium \\ ${ }^{2}$ Dept. of Emergency, Erasme University Hospital, Brussels, Belgium \\ Email: *Qjiangan@gmail.com
}

How to cite this paper: Qu, J.G., Mélot, C. and Appelboom, T. (2017) Synofit Premium in Refractory Low Back Pain: A Retrospective Observational Study. Open Journal of Rheumatology and Autoimmune Diseases, 7, 120-127.

https://doi.org/10.4236/ojra.2017.72011

Received: February 7, 2017

Accepted: May 24, 2017

Published: May 27, 2017

Copyright () 2017 by authors and Scientific Research Publishing Inc. This work is licensed under the Creative Commons Attribution International License (CC BY 4.0).

http://creativecommons.org/licenses/by/4.0/

\begin{abstract}
In this retrospective observational study, information about pain and quality of life was collected for analysis from medical records of 85 patients with chronic low back pain who were treated for 3 months with Synofit ${ }^{\oplus}$ Premium ( 2 - 3 capsules daily), a liquid mixture of green-lipped mussel from New Zealand, blackcurrant leaf, and curcuma extract. Within the first 6 weeks of therapy, a significant clinical benefit was observed for relief from pain, need for pain-relieving drugs, and the interference of pain with personal care and lifting. This benefit was more pronounced at 3 months. The mixture was well tolerated without significant side effects. Adherence was estimated to be "good" to "very good." Patients assessed global improvement and efficacy as "sufficient" to "good." Based on this study, the mode of action of Synofit Premium appears mainly to be analgesic, as reported by patients, and allows them to reduce the consumption of other pain-relieving substances and improve their quality of life. In conclusion, Synofit ${ }^{\circledR}$ Premium holds potential as a promising candidate alternative therapy for relief of low back pain and likely other painful rheumatic conditions, with almost no or minor side effects.
\end{abstract}

\section{Keywords}

Low Back Pain, Synofit, Osteoarthritis, Curcumin, Blackcurrant Leaf, Perna canaliculus, Curcuma longa, Ribes nigrum

\section{Introduction}

Synofit ${ }^{\oplus}$ Premium is a liquid mixture made from green-lipped mussels from New Zealand (Perna canaliculus), blackcurrant (Ribes nigrum) leaf, and curcumin (Curcuma longa). It has been proposed as a natural medicine in osteoarthritis and related conditions for several reasons. Results of as a systematic review suggest that a Perna canaliculus supplement may be superior to placebo in the treatment of 
mild to moderate osteoarthritis [1], probably linked to an analgesic effect. In addition, Perna canaliculus inhibits the 5-lipoxygenase and cyclo-oxygenase 1 and 2 pathways [2], which lead to the formation of the leukotrienes and prostaglandins that contribute to the inflammatory process [3] [4]. Ribes nigrum leaf, which is particularly rich in polyphenols, is among the most active extracts for inhibiting cytosolic phospholipase A2 alpha [5], and curcumin has been used for a long time in complementary medicine for a series of conditions, including osteoarthritis, because of its anti-inflammatory and anti-oxidant effects [6] [7] [8].

Osteoarthritis and particularly low back pain are among the most frequent health problems that patients report. Low back pain affects different age categories and is frequently chronic. Patients are often disappointed or experience side effects with regular treatment; consequently, they seek alternative therapies, including so-called natural therapies.

Synofit ${ }^{\oplus}$ Premium is marketed in the Netherlands, Germany, Spain, the United Kingdom, Switzerland, Slovakia, and recently in Belgium. Patients suffering from low back pain report an appreciation of the results of Synofit ${ }^{\oplus}$ Premium treatment ( 2 - 3 capsules daily for 1 - 3 months).

For these reasons, we performed a retrospective observational study based on the experience of five rheumatologists during 2016. Rheumatologists were asked to review their medical records to screen for patients who were treated for low back pain by Synofit ${ }^{\oplus}$ Premium for at least 3 months. The recorded routine clinical parameters (e.g., pain severity, benefit, side effects) were collected, particularly the results of the Dallas Pain Questionnaire. The use of this questionnaire is convenient in clinical practice because it is rapidly completed and represents a good instrument for monitoring low back pain.

\section{Patients and Methods}

\subsection{Patients}

A total of 156 medical records of adult patients suffering from low back pain and treated by Synofit ${ }^{\circledR}$ Premium during 2016 were retrospectively reviewed. Those who met the inclusion criteria were selected for analysis. These criteria included low back pain lasting more than 3 months, with medical imaging (spine X-ray and/or CTs can and/or MRI) indicating osteoarthritis defined as disc alteration, bone remodeling, and/or presence of osteophytes, and unresponsive to a current anti-inflammatory drug, pain-relief drug, and/or physical therapy. Patients used 2 - 3 Synofit $^{\oplus}$ Premium capsules daily. Each capsule contained $100 \mathrm{mg}$ liquid GLMax $^{\circledast}$ green-lipped mussel, $55 \mathrm{mg}$ blackcurrant leaf extract (1:10), $30 \mathrm{mg}$ BCM-95 ${ }^{\circ}$ curcumin, $17 \mathrm{mg}$ vitamin $\mathrm{C}, 7.4 \mathrm{mg}$ calcium, and $0.25 \mu \mathrm{g}$ vitamin D3.

\subsection{Clinical Parameters}

When available from the medical records, the following parameters were recorded: 0 to 10 visual analog scale values to evaluate pain severity, the 16 questions of the Dallas questionnaire (16 questions evaluated on a 0 to 10 numeric scale), adherence with therapy $(0=$ null, $1=$ low, $2=$ fair, and $3=$ good $)$, im- 
provement in global condition $(0=$ no, $1=$ little, $2=$ average, $3=$ great $)$, efficacy $(0=$ no, $1=$ moderate, $2=$ good, $3=$ very good $)$, reduction in NSAID $(0=$ no, 1 $=$ yes $)$ and analgesic $(0=$ no, $1=$ yes $)$ use, and side effects $(0=$ no, $1=$ yes $)$.

\subsection{Evaluation of Potential Benefit}

Comparisons between before treatment (baseline), after 6 weeks, and after 3 months were performed for each of the 16 items of the Dallas questionnaire and the four general components: daily life (questions 1 - 7), professional and leisure activities (questions 8 - 10), anxiety-depression (questions 11 - 13), and sociability (questions 14 - 16). After being regrouped into components, the Dallas score was calculated following transformation of the initial 0 to 10 scale into a space $0-5$ scale.

\subsection{Statistical Analysis}

The binary variables were compared using the $\mathrm{Chi}^{2}$ test. The scaled variables (from 0 to 10 or from 0 to 3 ) were compared using non-parametric tests because their distribution was non-Gaussian (using the Shapiro-Wilk test: 11 variables were Gaussian and 54 non-Gaussian), except for age, which was expressed as mean \pm standard deviation. Because of the important attrition of patients over time (baseline, $\mathrm{n}=85 ; 6$ weeks, $\mathrm{n}=61 ; 3$ months, $\mathrm{n}=17$ ), the three periods of treatment were tested using the Kruskal-Wallis non-parametric test, and pairwise comparisons were made using the Wilcoxon rank sum test. The results are expressed as medians and interquartile ranges (IQRs: P25 to P75) in the text or as medians with $95 \%$ confidence intervals in the figures.

\section{Results}

\subsection{Population Characteristics}

Data were collected and analyzed for 85 of 156 patient medical records (mean age: $69 \pm 3$ years; M:F sex ratio: 24/61). Of these 85 records for baseline data, 61 were evaluable at 6 weeks and 17 at 3 months. The median duration of low back pain was 54 months (IQR: 12 to 120 months).

\subsection{Clinical Evaluation}

\subsubsection{Benefit on Pain Severity}

The administration of Synofit ${ }^{\circledast}$ Premium significantly reduced pain severity within the first 6 weeks $(p=0.0006)$. This benefit lasted for 3 months, but the improvement did not increase further $(\mathrm{p}=0.634)$ (Figure 1$)$.

\subsubsection{Benefit on Quality of Life in Low Back Pain}

Regarding the quality of life of patients with low back pain, three symptoms concerning daily life from component 1 (Q1 to Q7) of the Dallas questionnaire were significantly improved: 1) the need for pain-relieving substances to be comfortable (Figure 2); 2) the interference of pain with personal care, such as getting out of bed, teeth brushing, and dressing (Figure 3); and 3) limitations on lifting an object (Figure 4). The benefit was significant within the first 6 weeks and lasted to 3 months. 
In contrast, the other items of the Dallas questionnaire were not significantly modified. These items included walking restriction, pain when sitting or standing for a long period, interference with sleeping, social life, traveling, or professional activity, control of anxiety and emotions, depression, impact on interpersonal relationships, need for social support, and reaction to others in terms of irritation, frustration, or anger due to low back pain.

\subsection{Adherence}

Adherence to the treatment reached 2.5 (between fair $=2$ and good $=3$ ) at 6 weeks and remained at 2.7 after 3 months.

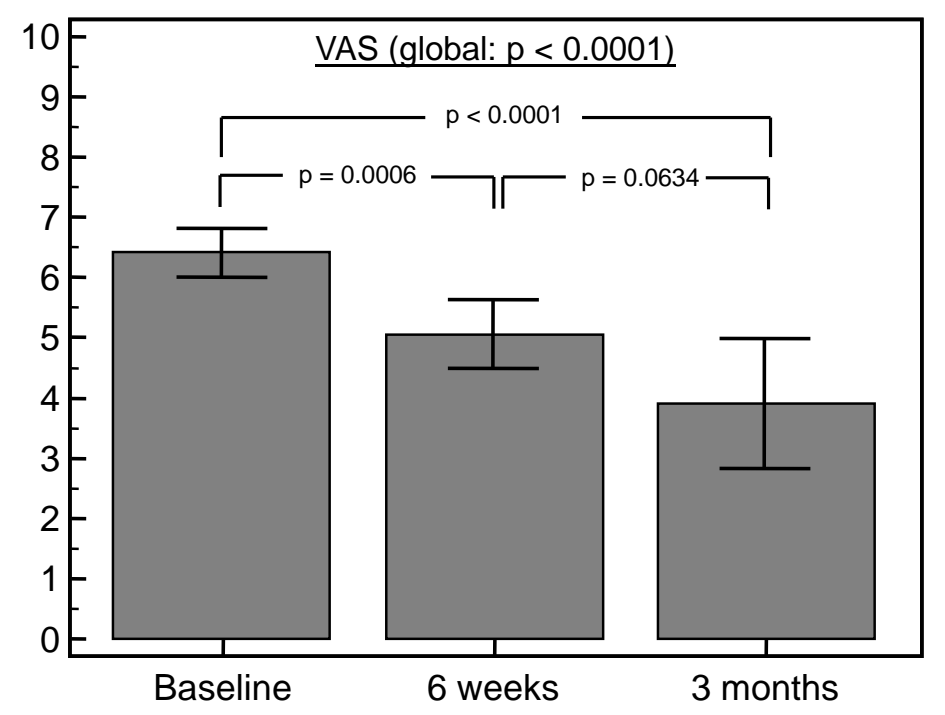

Figure 1. Pain reduction evaluated by the Visual Analog Scale (VAS) at 6 weeks and 3 months of Synofit ${ }^{\oplus}$ Premium administration. Bars show medians with $95 \%$ confidence intervals.

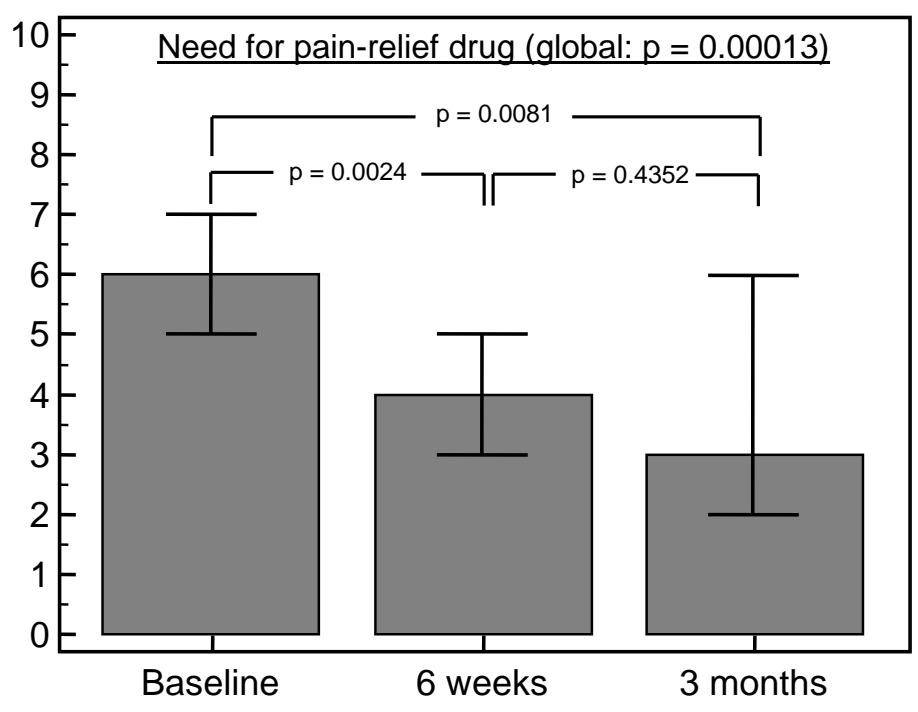

Figure 2. Reduction in the need for pain-relief drugs at 6 weeks and 3 months of Synofit $^{\circledast}$ Premium administration. Bars show medians with $95 \%$ confidence intervals. 


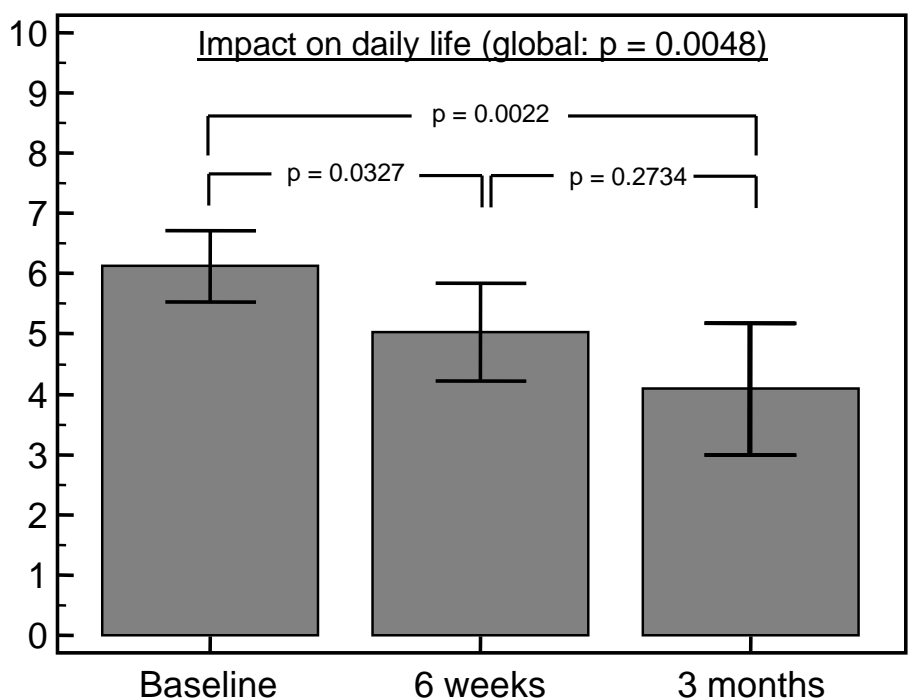

Figure 3. Decreased impact of low back pain on daily life at 6 weeks and 3 months of Synofit ${ }^{\oplus}$ Premium administration. Bars show medians with $95 \%$ confidence intervals.

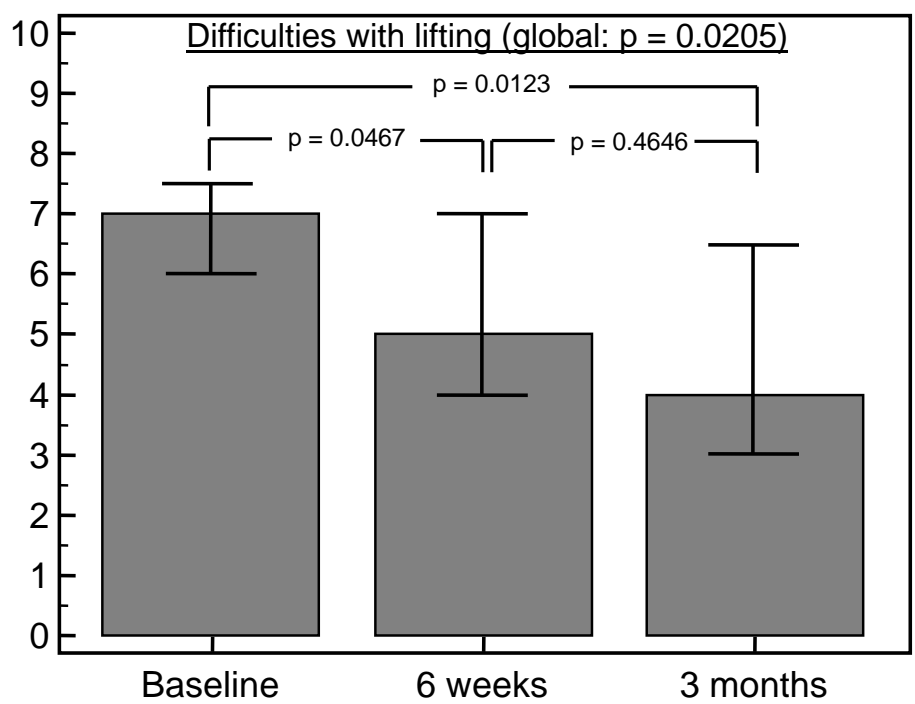

Figure 4. Reduction in difficulties with lifting at 6 weeks and 3 months of Synofit ${ }^{\star}$ Premium administration. Bars show medians with $95 \%$ confidence intervals.

\subsection{Patient Global Assessment of Improvement and Efficacy}

The satisfaction expressed by the patient regarding global improvement of the condition was graded between little $(=1)$ and average $(=2)$ at 6 weeks and had improved somewhat more at 3 months but did not reach statistical significance $(\mathrm{p}=0.1545)$. The efficacy was reported to be between moderate $(=1)$ and good $(=2)$ at 6 weeks and had improved somewhat more at 3 months but did not reach statistical significance $(\mathrm{p}=0.113)$.

\subsection{Adverse Events}

Except for 2 of 85 patients who reported a slight transient diarrhea at the beginning of treatment and $3 / 85$ who indicated difficulty with capsule swallowing 
(without therapy interruption), no adverse effect was reported.

\section{Discussion}

In this retrospective study based on the clinical experience of five rheumatologists and the medical records of 85 patients (at baseline) suffering from chronic low back pain, the administration of Synofit ${ }^{\oplus}$ Premium reduced not only pain severity but also the need for pain-relief drugs to ensure patient comfort. The interference of pain with daily life activities and limitations on lifting, which were the main complaints with low back pain, was also improved. Consequently, Synofit ${ }^{\oplus}$ Premium brought to these patients a significant benefit for their quality of life. This benefit was achieved within the first 6 weeks of therapy and lasted for the 3 months of administration with only a few minor and transient adverse events.

Of interest, adherence was between "fair" and "good." The global assessment by the patient of improvement and patient assessment of efficacy were "little" to "average" and "moderate" to "good", respectively, confirming the benefit in terms of pain, daily life activities, and lifting, as measured by the different components of the self-administered Dallas questionnaire.

The reason for the other components of the Dallas questionnaire remaining unchanged may be that their scores were only slightly altered before treatment, indicating that these symptoms were less prominent. In other words, difficulties with walking, sitting, standing, and interference with sleeping were not a significant complaint at baseline and did not affect the quality of life of the patient.

In addition, for most of the patients, low back pain did not interfere with social life, traveling, or work. Furthermore, at baseline, it did not affect anxiety, mood, depression, or relationships; consequently, no change was observed in these areas with the use of Synofit ${ }^{\circledast}$ Premium.

It is important to note that the significant improvements during therapy were observed in the most altered Dallas questionnaire items concerning pain and consumption of pain-relief drugs. However, we did not determine the minimal clinically important difference for each item of the Dallas questionnaire. Nevertheless, additional questions from the questionnaire were included, such as a subjective assessment of improvement and treatment efficacy. The response varied from "little" to "average" and from "moderate" to "good", respectively, indicating a sufficient improvement with the therapy.

The mode of action of Synofit ${ }^{\oplus}$ Premium is not well documented. Nevertheless, pain and the need for pain-relief drugs were reduced, indicating an improvement in mobility and comfort for the patient. The benefit occurred relatively quickly, within the first 6 weeks. The most likely explanation is an analgesic effect; thus, the mechanism could be due to an anti-inflammatory influence on signaling cascades involving phospholipase, cyclo-oxygenase, or lipoxygenase or a direct effect on neural pain mechanisms. Anxiety, mood, and related symptoms were not affected, so it is unlikely that Synofit ${ }^{\bullet}$ Premium influences the associated pathways. 
All patients had complained of chronic low back pain and had been treated by a large arsenal of therapies without sufficient benefit, yet seemed to respond to Synofit ${ }^{\otimes}$ Premium therapy. This observation supports the potential benefit of Synofit ${ }^{\oplus}$ Premium in refractory low back pain.

In a previous open-label study in a small group of patients with low back pain and knee osteoarthritis, within 4 weeks of Synofit ${ }^{\oplus}$ Premium treatment, the participants experienced improvements in pain, physical condition, and global assessment of a benefit in terms of quality of life, but not for joint stiffness; however, fibromyalgic patients did not report these benefits [9]. The present study extends the duration of administration up to 3 months, the number of patients from 25 to 85 , and the number of items for evaluating quality of life from one to 16 ; the results confirm the benefits seen in the first, smaller study.

The interpretation of both real-life studies is difficult because the clinical trial methodology is rather limited; only quality of life questions were used, and consequently, a placebo or clinician-related effect cannot be excluded.

In this study, only pain parameters were affected; no mechanical symptoms related to lumbar pain, such as pain during walking or standing, or emotional symptoms were altered by Synofit ${ }^{\circledast}$ Premium. In terms of pain, it is possible that Synofit ${ }^{\circ}$ Premium brings a real benefit to these patients and can offer them an alternative to analgesic or anti-inflammatory drugs generally used in this condition.

Participating physicians: Delia Comsa MD, Angelica Gal MD, Mihahella Maruseac MD, Laurie Waroquier MD, Division of Rheumatology and Physical Medicine, IRIS Hospitals, Brussels, Belgium.

\section{References}

[1] Brien, S., Prescott, P., Coghlan, B., Bashir, N. and Lewith, G. (2008) Systematic Review of the Nutritional Supplement Perna canaliculus in the Treatment of Osteoarthritis. Q JMed, 101, 167-169. https://doi.org/10.1093/qjmed/hcm108

[2] Coulson, S., Vecchio, P., Gramotnev, H. and Vitetta, L. (2012) Green Lipped Mussel Extract Efficacy in Knee Osteoarthritis and Improvement in Gastrintestinal Dysfunction: A Pilot Study. Inflammopharmacology, 20, 71-76. https://doi.org/10.1007/s10787-012-0128-6

[3] Treschow, A., Hodges, L., Wright, P.F.A., Wynne, P.M., Kalafatis, N. and Macrides, T.A. (2007) Novel Anti-Inflammatory Omega-3 PUFAs from the New Zealand Green Lipped Mussel Perna canaliculus. Comparative Biochemistry and Physiology, 147, 645-656.

[4] McPhee, S., Hodges, L.D., Wright, P.F.A., Wynne, P.M., Kalafatis, N., Harney, D.W. and Macrides, T.A. (2007) Anti-Cycloogenase Effects of Lipid Extracts from the New Zealand Green-Lipped Mussel, Perna canaliculus. Comparative Biochemistry and Physiology, 146, 346-356.

[5] Angenot, L., Bassleer, C., Dams, J. and Tits, M. (2002) Effects of Prodelphinidins Isolated from Ribes nigrum on Chondrocyte Metabolism and Cox Activity. Naunyn-Schmiedeberg's Archives of Pharmacology, 365, 434-441. https://doi.org/10.1007/s00210-002-0553-y

[6] Arnold, E., Benz, T., Zapp, C. and Wink, M. (2015) Inhibition of Cytosolic Phos- 
pholipase A2 Alpha by Medicinal Plants in Relation to Their Phenolic Content. Molecules, 20, 15033-15048. https://doi.org/10.3390/molecules200815033

[7] Deodhar, S.D., Sethi, R. and Srimal, R.C. (1980) Preliminary Study on Antirheumatic Activity of Curcumin (Diferuloyl Methane). Indian Journal of Medical Research, 71, 632-634.

[8] Kuptniratsaikul, V., Thanakhumtorn, S., Chinswangwatanakul, P., Wattanamongkonsil, L. and Thamlikitkul, V. (2009) Efficacy and Safety of Curcuma domestica Extracts in Patients with Knee Osteoarthritis. The Journal of Alternative and Complementary Medicine, 15, 891-897. https://doi.org/10.1089/acm.2008.0186

[9] Qu, J.G., Mélot, C. and Appelboom, T. (2015) Short Report of a Preliminary Open Study of Synofit Containing Bio-Curcumin, Greenlipped mussel and Blackcurrant Leaf Extract in Arthritis. Open Journal of Rheumatology and Auto-immune Diseases, 5, 113-117. https://doi.org/10.4236/ojra.2015.54018

\section{Submit or recommend next manuscript to SCIRP and we will provide best} service for you:

Accepting pre-submission inquiries through Email, Facebook, LinkedIn, Twitter, etc. A wide selection of journals (inclusive of 9 subjects, more than 200 journals)

Providing 24-hour high-quality service

User-friendly online submission system

Fair and swift peer-review system

Efficient typesetting and proofreading procedure

Display of the result of downloads and visits, as well as the number of cited articles Maximum dissemination of your research work

Submit your manuscript at: http://papersubmission.scirp.org/

Or contact ojra@scirp.org 